\title{
Alessandro Capone The pragmatics of pronominal clitics and propositional attitudes ${ }^{1}$
}

\begin{abstract}
In this paper I have used pronominal clitics in Italian in combination with verbs of propositional attitude to shed light on opacity effects due to intrusive pragmatics (at the level of free enrichments/explicatures). Certain problems discussed by Schiffer (2000) disappear completely, when the syntax, semantics and pragmatics of propositional clitics are discussed and such considerations are extended to propositional attitudes in general. In this paper, I add that a propositional clause must be in an appositional relationship (resulting from free enrichment and, thus, not actually present in the syntax) with the that-clause embedded in verbs of propositional attitude. I consider the consequences of this position. One of the most cogent results of this paper is that pronominal clitics generally refer back to full propositions (if they refer to propositions at all) and not to minimal propositions. I take my own considerations on clitics to give support to interesting and important considerations on emergent presuppositions by Kecskes and Zhang (2009).
\end{abstract}

Keywords: presupposition, pronominal clitics, propositional attitude, common ground, subordination

Alessandro Capone: E-mail: alessandro.caponis@gmail.com

\begin{abstract}
The socio-cognitive approach emphasizes that common ground is a dynamic construct that is mutually constructed by interlocutors throughout the communicative process. The core and emergent components join in the construction of common ground in all stages, although they may contribute to the construction process in different ways, to different extents, and in different phases of the communicative process. (Kecskes and Zhang 2009: 331)

... let us say that a TEXT is a set of instructions from a speaker to a hearer on how to construct a particular DISCOURSE MODEL. The model will contain DISCOURSE ENTITIES, ATTRIBUTES, and LINKS between entities. (Prince 1981: 235)
\end{abstract}

1 I would like to give thanks to Eleni Gregoromichelaki for her precious bibliographical help and advice. Jim Higginbotham has provided very useful considerations. I would also like to thank Istvan Kecskes, Igor Douven, Wayne Davis, Yan Huang, Louise Cummings, and Klaus von Heusinger. 


\section{Introduction}

In this paper, I am going to discuss presuppositional clitics in combination with verbs of propositional attitude (factive and non-factive). Combination with nonfactive verbs of propositional attitude is important insofar as it shows that the presuppositional phenomena triggered by clitics do not derive from (semantic) properties of the verbs in question (see also Higginbotham p.c.). I shall mainly discuss a language like Italian, even if in Capone (1997, 2000) I collected data from various European pro-drop languages and I compared my own intuitions about presuppositionality with those of native speakers of those languages. It is generally accepted in the literature on clitics that languages like Spanish display clitic doubling constructions, while languages like Italian or Greek ${ }^{2}$ do not. Yet, even in Italian there is a phenomenon that looks like clitic doubling. Consider, in fact, the following utterances (discussed in Capone 1997, 2000, 2002, 2003, 2008, 2012):

(1) Giovanni lo sa che Maria è al cinema

(Lit. 'Giovanni it knows that Maria is at the cinema')

(2) Maria lo immaginava che Giovanni era al cinema

(Lit. 'Maria it imagined that Giovanni was at the cinema')

(3) Maria lo aveva capito che Giovanni era a Parigi

(Lit. 'Maria it had understood that Giovanni was in Paris')

(4) Maria lo aveva indovinato che Giovanni era a Parigi

(Lit. 'Maria it had guessed that Giovanni was in Paris')

(5) Maria lo aveva sentito che Giovanni era a Parigi

(Lit. 'Maria it had heard that Giovanni was in Paris')

(6) Maria lo aveva intuito che Giovanni era a Parigi

(Lit. 'Maria it had surmised that Giovanni was in Paris')

(7) Maria lo aveva notato che Giovanni era a Parigi

(Lit. 'Mary it had noticed that Giovanni was in Paris')

Some of the verbs in question are factive and some are not; yet all utterances appear to host constructions that look like clitic-doubling. I shall mainly refer to the constructions above as presuppositional or pronominal clitics.

Before proceeding further, I need to clarify one point. In this paper I connect the issue of pronominal clitics with the issue of definiteness. Scholars busy with

2 The literature on Greek is not unanimous, and some authors go for clitic doubling, as noted by a referee. See also Anagnostopoulou (2007). This is not a problem for my views. 
the issue of definiteness have normally concerned themselves with things such as existential presuppositions. However, I will mainly take up that strand of research that considers the notion of familiarity (Christophersen 1939; Prince 1992). According to Prince (1992), definite descriptions correlate with pieces of information that are hearer-old (indefinite descriptions, instead, correlate with pieces of information that are hearer-new). In this paper, I consider clitics as instructions (to use a term by Prince) to link to a previous segment of discourse. I formalize a bit this basic idea by recourse to von Heusinger's ideas on definiteness and choice functions.

In line with these considerations, it is likely that the presuppositions of pronominal clitics are introduced in discourse through a pronominal establishing an anaphoric link with an antecedent (a referent/proposition). Since anaphora and definiteness are considered two sides of the same familiarity principle (Peregrin and von Heusinger 2003), I take pronominal clitics in Italian to be presuppositional triggers, involving reference to some proposition that is salient in discourse. I assume that an NP is definite if the referent it introduces is functionally connected with some other discourse item that has been introduced previously. This position accords both with the considerations in Capone (2000) ${ }^{3}$ and in Nocentini (2003), ${ }^{4}$ who, taking up such considerations, extends them to clitics that are not copies of propositions, but of bare NPs (non-propositional NPs denoting things, rather than facts). Nocentini goes for a similar analysis, saying that both types of objects, when referred to anaphorically through a clitic, express topical information (read: given information). It is intuitive that the anaphoric properties of presuppositional clitics correlate with their ability to escape modal effects (mainly opacity), as in the following example:

(8) Giovanni lo vuole vendere, il suo violoncello ${ }^{5}$

(Lit. 'Giovanni it wants to sell his cello')

According to Heim (1992), strictly speaking, the verb "want” creates opacity and marks the object position as potentially non-referential, even if, normally, the English translation of the sentence in (8) is understood as having the presupposition that John has a cello, and that he does not only believe that. This is a case of presupposition accommodation through a conversational implicature, since in a prototypical scenario people who have beliefs have appropriate evidence for

3 Also see Leonetti (2007), who takes up considerations in Capone (2000).

4 Nocentini agrees with Capone that the doubling of a propositional object by a clitic is typically associated with factivity.

5 I take this to be a case of right dislocation, different from clitics doubling. 
them and can justify them, should they be challenged. It is interesting that in the Italian translation, when the clitic is present, the object position of the embedded clause is referential, either because the clitic refers to some previous item in discourse (not just to an NP but to an NP in a referential position), or because the presupposition is accommodated through some conversational implicature, due to the prolixity of the clitic construction. I reserve this second explanation for cases that cannot be accounted for through anaphora. I have briefly mentioned the issue of the opacity of the NP position embedded in a verb of propositional attitude like "believe." This question will be addressed later on. For the time being, it is clear that both propositional and non-propositional objects doubled by (presuppositional) clitics in Italian have special referential properties derivable through anaphoric connections or through conversational implicatures (M-implicatures to follow the terminology in Huang (2000)6).

\section{The syntax and semantics of pronominal clitics}

In this section, I shall review some of the recent and less recent proposals on (presuppositional) clitics and the syntax/semantics interface, focusing on the interpretational problem (see Anagnostopoulou 2007; Zwicky 1985; and van Riemsdijk 1999 for some generalizations on grammatical and phonological properties of clitics). Some of the recent pragmatic proposals (see Leonetti 2007 on deriving specificity from definiteness at the level of the explicature) essentially follow from the semantic ones. While previous discussions of clitics seemed to associate them with special specificity effects (see Sportliche 1993; DobrovieSorin 1990), more recent proposals seem to avoid the reference to specificity, while they link the pronominal clitics to definiteness effects. Leonetti (2007) is one of the strongest proponents of the idea that pronominal clitics correlate with definiteness, which essentially follows from the fact that the clitic has anaphoric properties.

Delfitto (2002) makes much of the anaphoric properties of pronominal clitics and relates definiteness effects to anaphoric properties. Since the pronominal clitic has anaphoric properties, it can link to previous discourse, either to connect with an NP (which refers to an object) or with a full proposition (still, syntactically, an NP). Definiteness features simply derive from the anaphoric properties of the clitic, since it is capable of referring to an entity that is highly salient and

6 M-implicatures can be dealt with by Relevance Theory by noticing the extra effort introduced by apparently redundant constructions and by offsetting such extra effort by some extra contextual effects. 
actually present in discourse. As von Heusinger and Kaiser (2003) suggest, we can assume that definiteness is a discourse-pragmatic property indicating that the discourse referent associated with a definite expression can be identified with an already introduced discourse item. Definiteness expresses familiarity in a discourse structure. For our purposes, we need to remind readers that both an object and a proposition can be familiar, if we associate it with an item that was introduced previously in a discourse (see also Farkas 2002).

Although the emphasis in this paper is on propositional attitudes (hence on salient propositions), clitics can refer back to objectual NPs. These anaphoric properties, which translate easily into definiteness effects, have been variously described in the literature under the name of Principal Filter Constraint, presuppositionality constraint, and context dependence (Guttiérez-Rexach 2000).

It is interesting that Leonetti (2007) supports his idea that definiteness - and NOT specificity - is involved in clitic doubling through the data offered by Capone (2000). Capone (2000) provides data on what Leonetti calls "clitics with complement clauses," such as the following:

(9) Maria lo sa che Giovanni è a Parigi

(Lit. 'Maria it knows that John is in Paris')

(10) Maria lo ha sentito che Giovanni è a Parigi

(Lit. 'Maria it has heard that John is in Paris')

(11) Maria lo ha sognato che Giovannni è a Parigi

(Lit. 'Maria it has dreamt that Giovanni is in Paris')

According to Capone (2000), these clitics introduce presuppositions, and thus, according to Leonetti (2007) an obvious way to unify the considerations by Capone (2000) with the considerations on objectual NP clitics is by giving up the specificity constraint, while holding on to the definiteness constraint. Pronominal clitics are said to refer back anaphorically to salient things, whether they be objectual things or propositions (my considerations are fully compatible with Ariel's (2008) important consideration that pronouns are normally associated with a high degree of activation and generally refer to salient things).

Gutiérrez-Rexach (2000) provides interesting considerations on the properties of clitics as being associated with Principal filters. Principal Filters properties are reduced by Leonetti (2007) to definiteness effects. What is clear is that Gutiérrez-Rexach, based on his Principal Filter constraint, bans examples such as the following:

(12) ${ }^{*}$ Le ho visto poche donne

(13) ${ }^{\star}$ Le ho viste tante donne 
While he obviously includes examples like the Spanish translation of:

\section{(14) L'ho visto Mario}

(Spanish involves clitic doubling; see also Janse (2008), who clearly associates clitic doubling with lack of an intonation break before the doubled DP). In (14) the clitic is associated with a General filter - there is a domain of entities to which Mario belongs (human beings), which is presupposed. Concerning (12), there is no set of "few women," which is presupposed. Presumably what Ho visto poche donne means is that the set of women I saw is smaller than the set of women I did not see. But there is no set such as "few women."

Now, a thorny question: Should we abandon the specificity constraint altogether? After all, this was the constraint that forced the interpretation of the following:

\section{(15) Mario lo vuole vendere il violoncello}

(Lit. 'Mario it wants to sell his cello')

as specific. In other words, the pronominal clitic prevents us from having access to an interpretation according to which the cello fails to refer to an object belonging to the extra-mental world (suppose Mario believes falsely he owns a cello, but he does not have one). Presumably, a movement analysis along the lines of Uriagereka (1995), by placing the clitic in a node c-commanding the node of the verb ("want" in this case), allows the clitic to escape the modal effects of "want." Being higher than "want," the clitic would have to be outside its scope, and this would explain why the non-modal interpretation is accessed. However, interesting and important though this analysis is, we have still to ascertain whether this analysis could be a consequence of another type of analysis (see Corver and Delfitto 1999). Corver and Delfitto (1999), in fact, propose that UNLIKE ordinary pronominals, clitics do not have inherent person features, but receive them from the verb and the special configuration in which they appear allows them to take these features from the verb. But now, I am not sure that the person features ( \pm human) really depend on the verb, although sometimes they do, as in the case of verbs of propositional attitude (sapere che, credere che, immaginare che), which ordinarily take propositional NPs. It is more reasonable to assume that the person features are inherited anaphorically through previously mentioned linguistic items, in which case (as also noted by Uriagereka 1995), the specificity effects of clitics would also follow from the requirement of taking person features anaphorically. Since modal subordination can occur anaphorically, specificity effects can be obtained for free. But now it seems to me that both person feature 
inheritance and specificity inheritance can be obtained for free - and furthermore specificity inheritance is nothing but a consequence of the definiteness effect obtained through the anaphoric effects of pronominal clitics. Modal subordination would ensure a specificity effect as well. Having said all this, the structural considerations illustrated by Uriagereka (1995) seem to me indispensible if not to grant specificity effects (or person features inheritance) to allow for anaphoric effects. The anaphoric effects, in other words, can be allowed only if there is the logical possibility that the sentence with a clitic pronoun can escape the modal effects of the main verb (e.g. 'want'); and for this to be possible, it is correct to posit that the clitic is situated in a syntactic node which is higher and c-commanding the verb node.

\section{Right dislocation vs. clitic doubling}

It may be argued that the constructions of interest to me in this paper, after all, are only cases of right dislocation (see Cardinaletti 2001). Now, while I accept that the cases where a pause is present are cases of clitic right dislocation, which involve topicalization (but not necessarily presupposition), I want to argue against the right dislocation analysis of propositional clitic doubling.

First of all, we can have dialogues like the following:

A: lo so.

B: Che cosa è che sai?

A: Che Maria è andata al cinema.

Like Kempson (2012), I take dialogicity (and the possibility of having utterances produced collaboratively) to reveal certain semantic properties of utterances. Here, B and A collaboratively proffer an utterance by their two distinctive utterances. When we put the two utterances together we obtain Lo so che Maria è andata al cinema, but it would be absurd to say that there is a pause here before the that-clause. All we have is a semantic reconstruction, which might very well be given an analysis similar to clitic doubling: Lo so pro1 [che Maria è andata al cinema]1. Now given that joint utterances may require an analysis different from clitic right dislocation, nothing can prevent us from seeing Lo so che Maria è al cinema as having a pronominal clitic, whose trace/pro is in an appositional relationship with the that-clause and conjoined with it semantically.

But most importantly, can one pronounce Maria lo sa che Giovanni è a Parigi without a pause before the that-clause? In standard Italian, I do not hear the pause, UNLESS sapere is focused (either contrastively or not). Both the clitic 
construction and the construction without the clitic can allow a speaker to focus sapere contrastively (NOT believes) contrary to predictions by Cardinaletti. So there could be a construction which is similar to clitic doubling and one which involves clitic right dislocation.

In this section I will maintain that, in Italian, clitic doubling (to be distinguished from clitic left dislocation, a construction studied by Cinque (1990) and discussed in Capone (2000) $)^{7}$ is possible in the case of propositional arguments (but not in the case of objectual arguments (DPs) that require an alternative construction (clitic right dislocation). In particular, I claim that it is possible to have two alternative constructions, with clitics, when there is a propositional argument, clitic doubling, and right dislocation. Right dislocation invariably requires a pause, which is missing in the case of the clitic doubling construction. So, in my view, it is possible to have the following structures:

(16) Giovanni lo sa che Maria è a Parigi;

('John it knows that Mary is in Paris')

(16b) Giovanni lo SA, che Maria è a Parigi.

('John it knows, that Mary is in Paris')

The pause in the case of the clitic right dislocation construction is (normally) preceded by Focus on the verb sapere ('know'). Our task is to show that clitic doubling is involved in the most ordinary construal of sentences such as (16). In standard Italian, the pause is missing in a construction such as (16). This is taken by the literature (on clitic doubling) to show that clitic doubling and NOT right dislocation is involved in this case (see Janse 2008).

The discussion above of the dialogic example in which a sentence such as (16) is broken into two conversational turns seems to me perhaps the most compelling type of evidence that clitic doubling is involved, as the right dislocation construction, invariably requiring a pause (and also a monologic utterance as its pragmatic host) does not seem to do justice to the dialogic breaking of the sentence in (16). However, it will be important to provide further justification for my analysis based on semantic evidence. An important piece of evidence is that certain factive verbs do not allow clitic doubling. Consider for instance the following:

(17) ?Giovanni lo rimpiange che sono stato a Parigi senza di lui.

(Lit. 'John it regrets that I was in Paris without him')

7 Che Giovanni è andato al cinema, Maria lo sa bene.

('That John went to the cinema, it Mary knows well.') 
This seems to be a case of a factive verb disallowing clitic doubling. However, things dramatically improve when right dislocation is the structure appearing in the sentence:

(18) Giovani lo rimpiange, che sono stato a Parigi senza di lui.

('John it regrets// that I was in Paris without him')

Now, this seems to me important evidence that the distribution of factive verbs in combination with clitics is sensitive to the distinction between clitic doubling and right dislocation. If things were not so, it would not be possible to explain why in the other types of factive verbs (e.g., sapere) both clitic doubling and right dislocation are possible. Similar pairs can be established by the following examples:

(19) ?Giovanni lo ribadisce che è stato a Parigi

('John it states again that he was in Paris')

(20) Giovanni lo ribadisce, che è stato a Parigi

('John it states again, that he was in Paris')

(21) ?Giovanni te lo rimprovera che sei stato a Parigi

(Lit. 'John it blames you that you were in Paris')

(22) Giovanni te lo rimprovera, che sei stato a Parigi

(Lit. 'John it blames you, that you were in Paris')

(23) ?Giovanni lo rinfaccia che sono stato a Parigi senza di lui

(Lit. 'John it always blames me that I was in Paris without him')

(24) Giovanni lo rinfaccia (sempre), che sono stato a Parigi senza di lui

(Lit. 'John it (always) blames me that I was in Paris without him')

(25) ??Giovanni lo presuppone che sono stato a Parigi senza di lui

('John it presupposes that I was in Paris without him')

(26) Giovanni lo presuppone, che sono stato a Parigi senza di lui

('John it presupposes// that I was in Paris without him')

More importantly, evidence in favor of clitic doubling, rather than right dislocation, comes from questions such as the following:

(27) Come lo sai che Maria è andata a Parigi?

(Lit. 'How do you it know that Mary went to Paris?')

Clitic doubling is allowed in the question (how question), but right dislocation is not really acceptable: 
(28) ${ }^{\star}$ Come lo sai, che Maria è andata a Parigi?

(Lit. 'How do you it know, that Mary went to Paris?')

(The sentence gets much better, however, with focal stress on SAI (know), but in this case the speaker is casting some doubt on the usage of sapere 'know' and identifying sapere (in a loose usage with) the weaker credere 'believe').

Similar considerations apply to the following pairs:

(29) In che modo lo hai scoperto che Maria è andata a Parigi?

(Lit. 'In what ways did you it find out that Mary went to Paris?')

(30) ^In che modo lo hai scoperto, che Maria è andata a Parigi?

('In what way did you it find out, that Mary went to Paris?')

(Things improve; however, if focus is placed on scoperto, which selects as alternatives verbs such as sentire 'hear,' thus weakening the factive presupposition.)

(31) Dove lo hai saputo che Maria è andata a Parigi?

('Where did you it find out that Mary went to Paris?')

(32) `Dove lo hai saputo, che Maria è andata a Parigi?

('Where did you it find out that Mary went to Paris?')

(Things, however, improve if focus in placed on saputo 'known,' which selects a class of alternatives such as for example venire a credere 'come to believe,' which seems to weaken the factive presuppositions considerably.)

Further evidence comes from ellipsis, which notoriously requires that the same formal type of constituent be elided:

(33) Giovanni lo sa bene che Maria è andata a Parigi e Giovanni pure [che Maria è andata a Parigi].

(Lit. 'John it knows well that Mary went to Paris and John too [that Mary went to Paris]')

However, ellipsis is not allowed in the following case:

(34) *Giovanni lo sa bene che Maria è andata a Parigi e Mario pure che Giovanni è a Londra.

The reason for this is that ellipsis requires that a constituent of the same type be elided. However, since $s a$ is not a constituent in itself, but requires a syntactic 
object and the two conjoined sentences have two different syntactic objects, ellipsis (of the verb) is not licit.

However, things change when right dislocation is considered:

(35) Giovanni lo sa bene, che Maria è andata a Parigi, e Mario pure, che Giovanni è a Londra.

The reason for this change is in that right dislocation construction, the elided constituent lo sa is of the same (abstract) type as that occurring in the conjoined sentence. In other words, clitic doubling involves a tighter relationship between the verb and the propositional argument than is the case with right dislocation. It appears that in right dislocation the comma marks a syntactic boundary as well.

Yes/no questions, furthermore, require clitic doubling constructions, as right dislocated structures instead either are not licit or in any case rather odd:

(36) ???Lo sai, che Mario è a Parigi?

('Do you it know, that Mario is in Paris?')

(37) Lo sai che Mario è a Parigi?

('Do you it know that Mario is in Paris?')

Things get much worse with if-questions, in which right dislocation is even worse than in questions such as (38):

(38) Lo sai se Mario è a Parigi?

('Do you it know whether Mario is in Paris?')

(39) ${ }^{*}$ Lo sai, se Mario è a Parigi?

('Do you it know, whether Mario is in Paris?')

((39) is more acceptable with focus on sai, in which case it selects credere and similar verbs as a class of alternatives (casting doubt on the fact that Mario is in Paris).

Wh-questions also seem to make clitic doubling compulsory, as the alternative right dislocated structure is very odd and nonsensical:

(40) Chi lo ha detto che Maria è a Parigi?

('Who it said that Mary was in Paris?')

(41) ????Chi lo ha detto, che Maria è a Parigi?

('Who it said, that Mary was in Paris?') 
(41) is more acceptable, if pronounced with focus on detto (choosing as possible class of alternatives verbs like sapere) actually casts doubt on the fact that Mary is in Paris.)

The right dislocation vs. clitic doubling analysis is also supported by the presence of the demonstrative pronominal, which is disallowed with clitic doubling, but allowed with right dislocation:

(42) *Non lo avrei mai immaginato questo/quello che Maria sarebbe andata a vivere a Roma.

('I would have never it imagined this/that that Maria would have ended up in Rome')

(43) Non lo avrei mai immaginato, questo/quello, che Maria sarebbe andata a vivere a Roma.

('I would have never it imagined, this/that, that Mary would have ended up in Rome')

The presence of la frase 'the sentence' furthermore correlates with clitic doubling, but NOT with right dislocation:

(44) Non l'avevo ancora sentita la frase che il vero è il falso.

('I had not yet it heard the sentence that what is true is false')

(45) *Non l'avevo ancora sentita la frase, che il vero è il falso.

('I had not yet it heard the sentence, that what is true is false')

However, if the demonstrative adjective is combined with la frase, the right dislocation structure, but NOT the clitic doubling structure is acceptable:

(46) Non l'avevo ancora sentita, questa frase, che il vero è il falso.

('I had not yet it heard, this sentence, that what is true is false')

(47) ???Non l'avevo ancora sentita questa frase che il vero è il falso.

('I had not yet it heard this sentence that what is true is false')

Cleft-sentences also provide evidence in favor of the clitic doubling vs. right dislocation distinction, as the right dislocation construction is not allowed in the cleft-construction:

(48) E' Giovanni che lo sa che Maria è andata al cinema.

('It is John who it knows that Mary went to the cinema')

(49) ???E' Giovanni che lo sa, che Maria è andata al cinema.

('It is John who it knows, that Mary went to the cinema') 
I take all this evidence to cumulatively demonstrate that doubling of propositional arguments through a clitic is possible in Italian and contrasts strikingly due to semantico/syntactic properties with right dislocation.

Suppose, however, for the sake of argument, that we agree with Cardinaletti and accept that the construction analyzed in this paper is a case of rightdislocation. Would things be different for our pragmatic theory? All Cardinaletti says about right dislocation is that it correlates with topicality. But topicality need not coincide with presuppositionality (I could say Anche io lo so and refer back to something said before, without accepting it, because I am using an ironic tone of voice). Topicality is an instruction to look at something said before (rather than something said later) and could be identified with a procedure in the sense of Blakemore (2000), something that facilitates inference but is not completely coincident with it. Even granting topicality, we need something like epistemic modal subordination to establish definiteness, which is the type of interpretation typically correlating with clitics.

\section{Definiteness}

In my opinion, pronominal clitics, in Italian, in clitic doubling are associated with definite interpretations. The definite interpretations of clitics could be modeled by resorting to choice functions (see Hilbert and Bernays 1939; Ionin 2006; Winter 1997; von Heusinger 2000; Peregrin and von Heusinger 2003), which select a certain referent in a given discourse, and are suitable for the purpose of expressing the relationship between a referent and a speaker (or a cognizer) (see Löbner 1985 for a functional approach to definiteness). In the case of pronominal clitics, the choice functions establish a triadic relationship between a given referent, $a$ speaker, and a cognizer. The relationship between the speaker and the referent must model the one between the cognizer and the referent. So, take for example a sentence such as Giovanni lo ha visto il violoncello. Given the definiteness effects of the clitic, there are two choice functions that select the same referent, one from the perspective of Giovanni and one from the perspective of the speaker. These two choice functions end up selecting the same referent. When the clitic simply refers back to a referent, the relationship between the speaker, the cognizer, and the referent is usually one guaranteed by the shared perceptual ties between the referent and the speaker/cognizer. It is true that the speaker and the cognizer may view the referent from different angles (one of them may even have a partial view of the referent), but the relationship between them and the referent is (usually) in presentia. However, when the clitic introduces a speaker/hearer presupposition (a whole proposition and not only a referent is presupposed), we can still model 
the relationship between the speaker, the cognizers, and the proposition through a choice function that selects a certain thing (an event or proposition or fact, in this case), but the relationship between the speaker/cognizer need not be one in presentia, since they may have come to know that the proposition is true at different times, and in different ways. So, while in the case of clitics that refer back to an NP (clitic right dislocation), different choice functions may end up selecting the same referent and the nature of the functions may be sufficiently similar (say, a perceptual relation), in the case of pronominal clitics that refer back to propositions (propositional clitic doubling), the choice functions end up selecting the same object (the same proposition), but the functions may be of a different nature - the speaker may have come to know the proposition by hearsay while the cognizer may have come to know the proposition by direct evidence (say, he saw the event happen) (see Peregrin and von Heusinger 2004 for a greater number of details on the formalization of choice functions in anaphoric patterns, in particular their idea that choice functions are of help in formalizing local and dynamic properties of discourse fits well with the idea that pronominal clitics introduce choice functions allowing anaphoric uptake. The relationship between a pronominal clitic and the antecedent, when there is an explicit one, is always of a local nature, extending to adjacency pairs). So, the idea that choice functions represent contextual information (von Heusinger 2003) can be put to the test by reference to the issue of pronominal clitics, which introduce very specific contextual requirements selecting propositions that are salient in the previous context. While readers can become familiar with the details of choice function theory (e.g., by reading Peregrin and von Heusinger 2003), we can informally say that the definiteness of definite descriptions or of clitic constructions can be captured by constructing sets of elements (the set is selected by the descriptive part of a definite description) and by imposing an order on them. An element (the most salient one) is chosen (selected); the function that selects this element can be represented as Фc, which is the result of applying the choice function to the set identified through the descriptive part of the definite description.

We may consider the relationship between the pronominal clitic and the thatclause embedded in a verb of propositional attitude by analogy with the properties of definite descriptions. Definite descriptions are constituted by a determiner and an NP; the NP provides a descriptive part, while the determiner allows the NP to be anaphorically linked to some previous entity (usually an indefinite description such as "a man." The structural complexity of the clitic doubling construction reminds us of that of a definite description. We have a constituent, which forces a definite interpretation; this constituent is the clitic, whose structural position (pre-verbal position) allows it to escape the modal effects (or the opacity effects) of the verb of propositional attitude; the other constituent is the that-clause, syn- 
tactically an NP, which provides a descriptive part. The sentential NP refers to a unique event or fact or proposition, but this is not built into the semantics of the that-clause, but only an epiphenomenal consequence of the anaphoric relationship established by the clitic, which anchors the sentential NP to some event or fact or proposition which was made salient by some previous discourse element (presumably another sentence with a VP, having an intrinsic position for events).

\section{Modal subordination}

Once we accept to explore the hypothesis that clitic doubling (in languages like Spanish) and pronominal clitics in Italian have anaphoric properties, linking the clitic to a previously asserted or voiced proposition, we are open to the possible suggestion that some kind of modal subordination (of the epistemic type) occurs between a proposition previously voiced or asserted, and the clitic and the proposition which doubles it (also see Capone 2002, 2003, based on Roberts 1989). Anaphora, in this scenario, is not confined to a propositional object, to which the clitic is anchored, but is extended to a propositional attitude. Is it possible that a propositional attitude is transmissible through anaphora? Now, there is something that helps us entertain this possibility. In fact, von Heusinger (2002: 3) claims that "the referent of a specific NP is functionally linked to the speaker of the sentence or to another referential expression in the sentence such as the subject and the object." The functional link between a subject and the referent of a specific NP is presumably a perceptual link (anyway a causal link) or a hearsay link (this position is more in line with the position that anaphora is responsible for definite/specific interpretations). Thus, it is reasonable to assume that a clitic encodes a procedure for establishing a function. Now, we may adopt and extend the idea of modal subordination (Roberts 1989) by assuming that the anaphoric link is not only one between the pronominal clitic and a proposition but one between a current utterance and a point of view previously expressed (either explicitly or implicitly). If we accept Williamson's (1996) idea that assertions have implicit modal parts, expressible by "I know that," then it is not impossible that the clitic will be anchored to these implicit modal attitudes. While Williamson's idea may be valid for robust categorical assertions, sometimes a speaker's commitment may be weaker than "I know that." So, in some cases, an assertion is not categorical, and may have, as part of its implicit modal, a verb that is weaker than knowledge. The continuum between full knowledge and weaker forms of knowledge (say hearsay knowledge, or knowledge by inference, etc.) is expressible through various sorts of modal elements, such as "I think that," etc. (see Capone 2001; Strawson p.c.). What is important to notice is that the expression of this 
modal element is part of the explicature; thus, even if it is expressed implicitly, it contributes to what is said. And if such is the case, we find a position for an implicit modal element in any of our assertions, whether categorical or not (an adjunct at the level of a sentential node, built as a consequence of free enrichment?). Now, the clitic will not only anchor the sentence to a previously expressed proposition, but also to a modal element previously expressed. ${ }^{8}$ And this is a kind of modal subordination, perhaps somewhat different from that described in Roberts (1989). Clearly, this little theory is testable not so much through verbs such as sapere 'know,' which are factive and, thus, involve a factive attitude to a proposition, which will end up being entailed, but through verbs such as "say" or "hear" or "understand." "Say" is the weakest of verbs of propositional attitude, if it is a verb of propositional attitude at all (doubts were voiced by Jaszczolt in personal communication). Consider the Italian case of dire 'say' with a pronominal clitic.

A: Maria dice che Giovanni è a Roma.

('Mary says that John is in Rome.')

B: Anche Mario lo ha detto che Giovanni è a Roma.

(Lit. 'Mario too it said that John is in Rome.')

Now, there may be more than one case. Suppose Maria is highly reliable, and we all know this to be the case. Then the knowledge chain from Maria to the speaker and through the speaker to the hearer (B) is quite reliable. There is very little reason to doubt Mary and what she said. The clitic lo in B's utterance links to an implicit modal element, possibly an implicit adjunct (and I know that what Maria said is reliable). B's utterance, then is a way to corroborate the point of view expressed through A's utterance in (50).

However, suppose we know that Mary is unreliable and it is mutually manifest that this is the case, then the clitic lo will be anchored to this point of view and the attitude to the proposition che Giovanni è a Roma is as weak as that implicit in A's assertion in (50).

\footnotetext{
8 A reviewer takes issue with my pragmatic story because he thinks that the pragmatic effects are independent of the syntax of clitics: "Issues of knowledge and reliability in interpretation are independent from the grammar of clitic pronouns and I do not see any reason to assume that the clitic is linked to an implicit modal element." But the reviewer has probably misunderstood my position, as my paper is to show that pragmatics, given the constraints of syntax, is able to provide modal interpretations. The pragmatics I have constructed is not dependent on the syntax, but must presuppose it. Free enrichments are usually obtained by furnishing constituents of thought that are combined with syntactic constituents actually present.
} 
Now, while this may be no more than a sketch of a solution, it is certainly interesting because it squares with at least two theories, one by Uriagereka (1995) and one by Roberts (1989). Not to mention the fact that the clitic ends up expressing a link between a proposition (something like the referent of the propositional NP) and the point of view of the cognizer of the verb of propositional attitude, along lines expressed by von Heusinger (2002). However, we have said previously that definiteness - and not specificity, which may be a consequence of an anaphoric link - is a characteristic of the clitics. Von Heusinger establishes identifiability as a criterion of definiteness - the definiteness indicates that the new referent is functionally connected with some other discourse item that has been introduced previously. However, as Leonetti argues, once we establish that an NP is definite, we can very well show that it is specific. Now it is true that this is subject to modal subordination, but at least in some cases, through modal subordination, definiteness will imply specificity.

Now that we have considered modal subordination a plausible hypothesis, we should recognize that, at least in some cases, verbs of propositional attitude can be used in combination with pronominal clitics in cases where there can be no plausible prior discourse allowing modal subordination. In such cases, the clitics, nevertheless, retain their presuppositional status (see also Capone 2003). The embedded proposition in such cases is not an emergent presupposition, according to important work by Kecskes and Zhang (2009), but a socio-cultural presupposition. Consider the following:

(51) Tutti lo sanno che Parigi è la capitale della Francia.

(Lit. 'Everybody it knows that Paris is the capital of France.')

The proposition is presupposed, presumably through a conversational inference triggered by the clitic. For those who are ready to object that, after all, sapere 'know' is factive and, thus, the embedded proposition is presupposed anyway, we may change the example and use capire or sentire or dire:

(52) Tutti lo hanno capito che Parigi è la capitale della Francia.

(Lit. 'Everybody it understood that Paris is the capital of France')

Furthermore, it should be added that factive verbs such as sapere 'know' can be used loosely. If capire and sentire are factive, they can also be used loosely. But when the clitic is present, they cannot be used this way. Thus, there is a strong presuppositional reading, which is implicated through the use of a presuppositional clitic or of clitic doubling. Both clitic doubling (in languages like Spanish) and pronominal clitics in Italian, involve a certain degree of redundancy. Thus it 
is not implausible that such redundancy (otherwise difficult to explain), involving greater cognitive efforts, must be offset by appropriate cognitive effects (to preserve the Principle of Relevance by Wilson and Sperber 2012), and thus will conversationally implicate a reading that is complementary to that of the construction where clitic doubling (or the pronominal clitic) is absent. We may follow Levinson (2000), Huang (2000), and Horn (2009) and claim that the prolixity generates a conversational implicature. The real difficulty, which may lead one to suspect that the inference is semantic, rather than pragmatic, consists in the fact that this inference is difficult to cancel. But this is in line with many types of M-implicatures. Since the prolixity may be used as a clue to interpretation $\mathrm{x}$, it is not easy to cancel $x$, since the prolixity remains otherwise unexplained. If we follow considerations by Relevance Theorists (see Carston 2002; Wilson and Sperber 2012), the prolixity equally gives rise to implicatures, since the speaker went for a construction involving greater processing efforts on the part of the hearer, and thus expected to obtain greater contextual effects, worth the efforts involved. Cancelling the implicature would require extra effort, and this is psychologically implausible, as Jaszczolt (2005) argues. On both the neo-Gricean and Relevanceinspired framework, we expect that the inference will not be easily cancelled.

\section{Do clitics link to (pragmatically enriched) propositions or to sentences?}

Before getting into the issue of propositional attitudes, which is central in this paper, I want to clarify a preliminary issue, which is whether clitics are anchored to full-fledged propositions or, otherwise, sentences. Logically speaking, it is not impossible for a clitic to refer back anaphorically to a sentence, a linguistic form (or even a lexeme) or to a phonetic string. However, it is natural that pronominal clitics refer back (anaphorically) to propositions. So, consider the following:

A: Scriviamo adesso il seguente esempio: "La mela è rossa."

('Let us now write the following example: "The apple is red"').

B: Anche io l'ho scritto che "la mela è rossa," Maestra.

(Lit. 'I also it wrote that "the apple is red,” Teacher.')

$A$ is a teacher and B is a child, who is exercising with writing letters of the alphabets and with writing very short and simple sentences. A clitic can be anaphoric and thus can link anaphorically with a linguistic form. The child may not even be 
aware of the meaning of the simple sentence; he is merely copying letters of the alphabet. Yet, the clitic establishes identity between the example given by the teacher and the product generated by the child when copying a linguistic string from the blackboard.

However, cases when pronominal clitics refer back anaphorically to a proposition are far more common. After all, I called these clitics presuppositional clitics because, at least when there is no context forcing modal subordination, the pronominal clitic serves to promote a proposition to the status of presupposed information (a presupposition). We may be interested in knowing whether pronominal clitics refer anaphorically to full-fledged propositions or, otherwise, to minimal propositions. In particular, we may want to know whether explicatures are also referred to anaphoricaly by clitics. Presumably a clitic should refer anaphorically both to the result of decoding and to the pragmatically obtained part of the explicature. So, consider the following case:

A: Mario è andato a Parigi e ha comprato un souvenir di Parigi.

('Mario went to Paris and bought me a souvenir of Paris.')

B: L'ho capito che Mario è andato a Parigi e ha comprato un souvenir.

(Lit. 'I it understood that Mario went to Paris and bought a souvenir.')

Through the clitic, B's utterance refers back to the utterance proffered by A and, in particular, to the proposition expressed, which is not only a minimal proposition but a full-fledged proposition, including the pragmatic component of the explicature. There is no need to make explicit the temporal relation between the two events expressed in A's utterance. Given pragmatic inferences, that much is clear, and the explicature (of temporal ordering) is part of the emergent presupposition (to use a term from Keckses and Zhang 2009). Emergent presuppositions are propositions that both the speaker and the hearer accept as a result of miniinteractions showing acceptance of a certain presupposition on the part of both the speaker and the hearer. Anticipating the term by Kecskes and Zhang (2009), Capone (2000) wrote of speaker/hearer presuppositions. This notion has been resisted for a while, but I am glad that Kecskes and Zhang (2009) came close to the concept I proposed in Capone (2000). The minidialogue in (54) is an interesting example of emergent presuppositions, since this type of presupposition requires mini-dialogues that ensure acceptance on the part of the speaker and the hearer of a certain proposition. But why is it that clitics, generally, do not refer anaphorically to minimal propositions? One reason for that is that pronominal clitics usually voice presuppositions, and what are presuppositions if not propositions presupposed by the speaker and the hearer. Since presuppositions 
are part of the common ground, it is obvious that they are fully enriched propositions, since the common ground ensures that all propositions present in the context interact with minimal propositions. Even if by using a clitic we tried to refer anaphorically to a minimal proposition, in some cases we could not, because/if the common ground, together with the principle of Relevance, promotes contextual enrichments that end up constituting a full proposition. An important intuition is that speaker's meaning prevails in mini-dialogues where pronominal clitics are used, provided that there are no evident clues that an example or a linguistic form is what is referred to by the clitic.

\section{Belief reports and pronominal clitics}

At this point, we want to reveal the most important purpose of this article, which is to use pronominal clitics to shed light on verbs of propositional attitudes. In this section I will develop considerations already put forward in Capone (2008), by making use of the syntactic apparatus already discussed. It should be pointed out that there are views (on pronominal clitics) different from the ones I have accepted. As Janse (2008) says, there are at least two syntactic positions on pronominal clitics:

a. The DP (Determiner Phrase) doubled by the clitic is an argument of the verb, and the clitic is a functional category (indicating agreement);

b. The clitic is base-generated (in argument position) and the DP (Determiner Phrase) has the status of an adjunct.

If one accepts position (b), then one may as well accept position (c), which was accepted in Capone (2008):

c. The DP (or the that-clause in the case of verbs of propositional attitude) is the main argument and the clitic (or its trace) is an apposition. Alternatively, we could consider the trace of the clitic or pro replacing the clitic and the DP as (jointly) a complex argument c-commanded by the verb, the clitic c-commanding the that-clause and the DP.

I now propose to abandon position (c), which may raise problems. Presumably, the steps involved in such an analysis are greater than those involved in the movement theory of clitics I accepted in this paper, as the trace of the clitic would have to move across an NP node and then across a VP node; alternatively, and preferably, we could have pro instead of the trace in a complex NP, but pro would have to be governed, and we would have to accept that a $\mathrm{V}$ node can govern a complex NP (consisting of pro and the that-clause) and government would then have to percolate down the NP node to each of its daughters, including pro; this explana- 
tion involves a greater number of steps than the position expressed in this article, which is basically the one proposed by Anagnostopoulou (2007): The clitic in pre-verbal position and pro in argument position are coindexed, and the DP that doubles the clitic is an adjunct or an apposition (adjoining to pro). The next step is to accept that the clitic can express a mode of presentation of the DP. The clitic expresses a mode of presentation of a proposition and, in particular, the fact that this proposition is given (or emergent from previous discourse, following Kecskes and Zhang 2009) and must be anaphorically linked to some previous proposition. Now, if one accepts syntactic theories based on movement of the clitic, then there is an empty category, e, which is in argument position, while the DP is in adjunct position (a position compatible with the positions normally occupied by syntactic appositions). Now, it is clear that the relationship between the clitic (in fact, its trace or pro associated to it if we do not think this empty category is a trace) and the DP is one of apposition, albeit the DP is an apposition to the trace of the clitic (alternatively, pro). So the clitic offers a mode of presentation of a proposition (the proposition embedded in the verb of propositional attitude). But now we may develop a parallel strategy and claim that the mode of presentation of the that-clause embedded in a verb of propositional attitude is an apposition of the that-clause. Unlike Schiffer (2000), I do not claim that opacity effects are obtained by a mode of presentation of an NP of the that-clause embedded in a verb of propositional attitude. Instead, I claim that the that-clause has a (complex, sentential) mode of presentation, provided through pragmatic enrichment (intrusion or free enrichment), and that can be adjoined syntactically to the that-clause in the way an apposition would be. This mode of presentation is complex and consists in copying linguistic materials of the that-clause. So while the elements of the thatclause contribute truth-conditional meaning expressed semantically (in particular, the references of NPs), the apposition clause adjoined through free enrichment contains the complex modes of presentation of the elements of the that-clause, thus allowing opacity. But now we have discussed the case of the mode of presentation contributed by a clitic and the mode of presentation contributed through free enrichment separately. Sometimes, we can have both contributions simultaneously, as in the following utterance:

(55) Giovanni lo sa che Maria è andata al cinema.

(Lit. 'John it knows that Mary went to the cinema.')

The clitic introduces a mode of presentation of the embedded proposition, indicating that it is given/presupposed/anaphorically linked to a previously voiced proposition (presumably a case of procedural meaning as discussed by Wilson and Sperber 2012). At an implicit level - to be made explicit through an 
explicature (Carston 2002; Wilson and Sperber 2012) - a constituent is added through free enrichment; however, not an apposition to individual DPs (as proposed by Bach 2000), but as an apposition to the S expressed by the that-clause. Such an apposition is complex and has the following syntactic shape: [NP VP], where NP and VP are copied from the linguistic materials present in the thatclause. Ample demonstration that opacity effects are to be incorporated into truth-conditional meaning - and thus are part of the explicatures and NOT of the implicatures of an utterance containing a verb of propositional attitude - has been provided in Capone (2008), thus I will not repeat it here. I will merely reiterate that while Salmon and followers try to deal with opacity effects at the level of implicatures, Capone (2008) deals with them at the level of the explicature.

The syntactic theory adopted here (certainly influenced by Anagnostopoulou 2007) allows us to avoid the complications of the view expressed in Capone (2008), while at the same time it allows us to express the explicatures of verbs of propositional attitudes in terms of appositive relationships between NPs (or sentential NPs) and a constituent provided through free enrichment respecting assumptions about syntax. In particular, by providing a complex/sentential mode of presentation of the that-clause, one has been allowed to provide individual modes of presentation for each constituent NP or VP of the that-clause. Compositionality has been respected, basically by ensuring that free enrichment does not violate the general syntactic rules of the language (see also Stanley 2007). Now, as Jaszczolt (2005) says, at the level of sentential semantics, verbs of propositional attitude appear to violate compositionality (because by replacing an NP having identical reference, one obtains different truth-conditions); however, at the level of merger representations (Jaszczolt 2005), which integrate semantic and pragmatic information, compositionality is preserved. The appositional syntax of free enrichment I have proposed has allowed us to preserve compositionality, as well as the syntactic constraint on pragmatic enrichment proposed by Stanley.

If pronominal clitics allow us to develop theoretical considerations on pragmatic enrichment that explain opacity effects (why we cannot freely replace an NP with an extensive one), we should also bear in mind that they themselves create other conversational effects that concern NP substitution. Consider the following mini-dialogue:

A: Maria sa che Giovanni è a Parigi.

('Maria knows that John is in Paris.')

B: Sì, ma anche Angela lo sa questo/che Giovanni è a Parigi.

(Lit. 'Yes, but Angela too it knows that John is in Paris.') 
Classical opacity effects consist in the requirement that one cannot replace the mode of presentation of the reference of an NP (say, Giovanni) with a different one (the two NPs being co-extensive). However, pronominal clitics introduce discourse requirements of their own. Since they introduce speaker/hearer presuppositions (what in other words Kecskes and Zhang in an important paper call emergent presuppositions), it will simply be illicit to replace, in the course of the minidialogue, a mode of presentation of the same reference (Giovanni) with another. Speaker/hearer presuppositions seem to concern not only the fact, but also modes of presentation of the reference. This is not surprising, since the same fact could not be recognized or shared, if NPs were freely replaced with modes of presentation which are not themselves part of speaker/hearer presuppositions. The requirement of speaker/hearer presupposition would not be satisfied if a mode of presentation of the reference different from the one used in the emergent presupposition is employed. And this presumably can be explained through the requirement of anaphoric uptake, which is obviously a textual matter, a matter of using a text that has been previously used. So there are three things at stake in this type of anaphoric uptake: a proposition, a stance to a proposition, and the mode of presentation of the proposition.

\section{Conclusion}

In this paper, I have put many threads together, in particular the theory on pronominal clitics (and clitic doubling) and the theory on propositional attitudes. It appears to me that pronominal clitics have a lot to say on the theory of conversational implicatures and can illuminate the issue of explicature. The most important considerations I have reached in this paper concern the general treatment of propositional attitudes, as pronominal clitics clearly indicate that the issue benefits from a treatment based on free enrichments built on appositional relationships. I think that through pronominal clitics we have bumped into something that looks like the right semantics and pragmatics for propositional attitudes.

\section{References}

Anagnostopoulou, Elena. 2007. Clitic doubling. In Martin Everaert \& Henk van Riemsdijk (eds.), The Blackwell companion to syntax, 519-579. Oxford: Blackwell.

Anderson, Stephen R. 2005. Aspects of the theory of clitics. Oxford: Oxford University Press. Aoun, Joseph. 1996. Clitic-doubled arguments. In Kyle Johnson \& Ian G. Roberts (eds.), Beyond principles and parameters, 13-42. Berlin: Springer. 
Ariel, Mira. 2008. Pragmatics and grammar. Cambridge: Cambridge University Press.

Atlas, Jay David. 1991. Topic/comment, presupposition, logical form and focus stress

implicatures: The case of focal particles only and also. Journal of semantics 8. 127-147.

Bach, Kent. 2000. Do belief reports report beliefs? In Kasia Jasczolt (ed.), The pragmatics of propositional attitude reports, 111-136. Elsevier: Oxford University Press.

Blakemore, Diane. 2000. Indicators and procedures: Nevertheless and but. Journal of Linguistics 36. 463-486.

Burton-Roberts, Noel. 2005. Robyn Carston on semantics, pragmatics, and 'encoding.' Journal of Linguistics 41. 389-407.

Capone, Alessandro. 1997. Modality and discourse. PhD dissertation, University of Oxford.

Capone, Alessandro. 2000. Dilemmas and excogitations: An essay on clitics, modality and discourse. Messina: Armando Siciliano.

Capone, Alessandro. 2001. Modal adverbs and discourse. Pisa: ETS.

Capone, Alessandro. 2002. Dilemmas and excogitations: Further considerations on modality, clitics and discourse. In Ken Turner \& Kasia Jaszczolt (eds.), Meanings in contrast, 147-176. Amsterdam: John Benjamins.

Capone, Alessandro. 2003. Theories of presuppositions and presuppositional clitics. In Peter Kühnlein, Hanne Rieser, \& Henk Zeevat (eds.), Perspectives on dialogue in the new millennium, 111-133. New York: John Benjamins.

Capone, Alessandro. 2008. Belief reports and pragmatic intrusion (the case of null appositives). Journal of Pragmatics 40. 1019-1040.

Capone, Alessandro. 2010. "Between Scylla and Charybdis": The semantics and pragmatics of attitudes 'de se.' Intercultural Pragmatics 7(3). 471-503.

Capone, Alessandro. 2010b. On the social practice of indirect reports. Further advances in the theory of pragmemes. Journal of Pragmatics 42(2). 377-391.

Capone, Alessandro. 2011. The attributive/referential distinction: Pragmatics, modularity of mind and modularization. Australian Journal of Linguistics 31(2). 153-186.

Capone, Alessandro. 2011b. Default semantics and the architecture of the mind. Journal of Pragmatics 43. 1741-1754.

Capone, Alessandro. 2011c. Knowing how and pragmatic intrusion. Intercultural Pragmatics 8(4). 543-570.

Capone, Alessandro. 2012. Between minds: Representing one's own and others' minds (through explicatures). PhD dissertation, University of Palermo.

Cardinaletti, Anna. 2001. Against optional and null clitics: Right dislocation vs. marginalization. University of Venice Working Papers in Linguistics, 11.

Carston, Robin. 2002. Thoughts and utterances: The pragmatics of explicit communication. Oxford: Blackwell.

Castañeda, Hector-Neri. 1966. "He": A study in the logic of self-consciousness. Ratio 8. 130-157.

Christophersen, Paul. 1939. The articles: A study of their theory and use in English. Copenhagen: Munksgaard.

Cinque, Guglielmo. 1990. Types of $A^{\prime}$-Dependencies. Cambridge, MA: MIT Press.

Corver, Norbert \& Denis Delfitto. 1999. On the nature of pronoun movement. In Henk C. van Riemsdijk (ed.), Clitics in the languages of Europe, 799-855. Berlin/New York: Mouton de Gruyter.

Delfitto, Denis. 2002. On the semantics of pronominal clitics and some of its consequences. Catalan Journal of Linguistics 1. 41-69. 
Dobrovie-Sorin, Carmen. 1990. Clitic doubling, Wh-movement, and quantification in Romanian. Linguistic Inquiry 21(3). 351-397.

Enç Mürvet. 1991. The semantics of specificity. Linguistic Inquiry 22(1). 1-25.

Farkas, Donka. 2002. Specificity distinctions. Journal of Semantics 19. 213-243.

Gunel, Jeanette K. 2003. Information structure and referential givenness/newsness: How much belongs in the grammar? In Stefan Müller (ed.), Proceedings of the HPSGO3 Conference. Stanford: CSLI.

Gutiérrez-Rexach, Javier. 2000. The formal semantics of clitic doubling. Journal of Semantics 16(4). 315-380.

Heim, Irene. 1992. Presupposition projection and the semantics of attitude verbs. Journal of Semantics 9. 183-221.

Higginbotham, James. 2003. Remembering, imagining, and the first person. In Alex Barber (ed.), Epistemology of Language, 496-535. Oxford: Clarendon Press.

Hilbert, David \& Paul Bernays. 1939. Grudlagen der mathematic, volume 2. Berlin/Heidelberg/ New York: Springer.

Holton, David, Peter Mackridge, \& Irene Philippaki-Warburton. 1997. Greek: A comprehensive grammar of the modern language. London: Routledge.

Horn, Laurence. 2009. Implicature, truth and meaning. International Review of Pragmatics 1. 3-34.

Huang, Yan. 2000. Anaphora: A cross-linguistic study. Oxford: Oxford University Press.

Huang, Yan. 2007. Pragmatics. Oxford: Oxford University Press.

Ionin, Tania. 2006. 'This' is definitely specific: Specificity and definiteness in article systems. Natural Language Semantics 14. 175-234.

Janse, Mark. 2008. Clitic doubling from Ancient to Asia Minor Greek. In Dalina Kallulli \& Liliane Tasmowski (eds.), Clitic doubling in the Balkan languages, 165-202. Amsterdam: John Benjamins.

Jaszczolt, Kasia. 2005. Default semantics: Foundations of a compositional theory of acts of communication. Oxford: Oxford University Press.

Karmiloff-Smith, Annette. 1992. Beyond modularity: A developmental perspective on cognitive science Cambridge. Cambridge, MA: MIT Press.

Kecskes, Istvan \& Fenghui Zhang. 2009. Activating, seeking and creating common ground. Pragmatics and Cognition 17(2). 331-355.

Kecskes, Istvan \& Fenghui Zhang. Forthcoming. On the dynamic relations between common ground and presupposition. In Alessandro Capone \& Francesco Lo Piparo (eds.), Perspectives on linguistic pragmatics. Dordrecht: Springer.

Kempson, Ruth. 2012. The syntax/pragmatics interface. In Ken Allan \& Kasia Jaszczolt (eds.), The Cambridge handbook of pragmatics, 529. Cambridge: Cambridge University Press.

Leonetti, Manuel. 2007. Clitics do not encode specificity. In Georg Kayser \& Manuel Leonetti (eds.), Proceedings of the workshop "Definiteness, specificity and animacy in IberoRomance languages.” Arbeitspapier: Fachbereich Sprachwissenschaft der Universität Constanz.

Leonetti, Manuel. 2008. Specificity in clitic doubling and in differential object marking. Probus 20(1). 33-66.

Lepore, Ernie \& Luvell Anderson. Forthcoming. Slurring words. Noûs.

Löbner, Sebastian. 1985. Definites. Journal of Semantics 4. 279-326.

Lyons, John. 1987. Semantics. In John Lyons, Richard Coates, Margaret Deuchar, \& Gerald Gazdar (eds.), New horizons in linguistics 2, 152-178. London: Penguin. 
Nicolle, Steve. 1998. A relevance theory perspective on grammaticalization. Cognitive Linguistics 9(1). 1-35.

Nocentini, Alberto. 2003. The object clitic in Italian: A functional interpretation. In Giuliana Fiorentino (ed.), Romance objects, 105-116. Berlin/New York: Mouton De Gruyter.

Peregrin, Jaroslav \& Klaus von Heusinger. 2003. Dynamic semantics with choice functions. Research on Language and Computation 2(3). 309-329.

Prince, Ellen. 1981. Toward a taxonomy of given-new information. In Peter Cole (ed.), Radical pragmatics, 223-256. New York: Academic Press.

Prince, Ellen F. 1992. The ZPG letter: Subjects, definiteness, and information status. In William C. Mann \& Sandra A. Thompson (eds.), Discourse description: Diverse linguistic analyses of a fund-raising text, 295-326. Amsterdam/Philadelphia: John Benjamins.

Recanati, Francois. 2010. Truth-conditional pragmatics. Oxford: Oxford University Press.

Roberts, Craig. 1989. Modal subordination and pronominal anaphora in discourse. Linguistics and Philosophy 12. 683-721.

Schiffer, Stephen. 2000. Propositional attitudes in direct-reference semantics. In Katarzyna Jaszczolt (ed.), The pragmatics of propositional attitude reports, 14-30. Elsevier: Oxford University Press.

Sportliche, Dominique. 1993. Clitic constructions. In Johan Rooryck \& Laurie Zaring (eds.), Phrase structure and the lexicon, 213-276. Bloomington, IN: IULC.

Stanley, Jason \& Timothy Williamson. 2001. Knowing how. Journal of Philosophy 98(8). 411-444.

Stanley, Jason. 2007. Language in context. Oxford: Oxford University Press.

Suñer, Margarita. 1988. The role of agreement in clitic-doubled constructions. Natural language and linguistic theory 6. 391-434.

Traugott, Elizabeth \& Richard Dasher. 2002. Regularity in semantic change. Cambridge: Cambridge University Press.

Uriagereka, Juan. 1995. Aspects of clitic placement in Western Romance. Linguistic Inquiry 23(1). 79-123.

van Riemsdijk, Henk. 1999. Clitics: A state of the art report. In Henk C. van Riemsdijk (ed.), Clitics in the languages of Europe, 1-30. Berlin \& New York: Mouton de Gruyter.

von Heusinger, Klaus. 2002. Specificity and definiteness in sentence and discourse structure. Journal of Semantics 19. 1-30.

Von Heusinger, Klaus. 2003. The double dynamics of definite descriptions. In Jaroslav Peregrin (ed.), Meaning in the dynamic turn, 150-168. Amsterdam: Elsevier.

Von Heusinger, Klaus (2004). Choice functions and the anaphoric semantics of definite NPs. Research on language and Computation 2, 309-329.

Von Heusinger, Klaus. 2011. Specificity. In Claudia Maienborn, Klaus von Heusinger \& Paul Portner (eds), Semantics: An international handbook of natural language meaning, Vol. 2, 996-1025. Berlin: Mouton de Gruyter.

von Heusinger, Klaus. Forthcoming. The salience theory of definiteness. In Alessandro Capone \& Francesco Lo Piparo (ed.), Perspectives on linguistic pragmatics. Dordrecht: Springer.

Von Heusinger, Klaus \& Georg A. Kaiser. 2003. The interaction of animacy, definiteness and specificity in Spanish. In Klaus von Heusinger \& Georg A. Kaiser (eds.), Proceedings of the workshop "Semantic and syntactic aspects of specificity in romance languages,"

Arbeitspapier 113, 41-65. Fachbereich Sprachwissenschaft: Universität Konstanz.

Warburton, Irene P. 1977. Modern Greek clitic pronouns and the 'surface structure constraints' hypothesis. Journal of Linguistics 13. 259-281. 
Williamson, Timothy. 1996. Knowing and asserting. The Philosophical Review 105(4). 489-523.

Wilson, Deirdre \& Dan Sperber. 2012. Meaning and Relevance. Cambridge: Cambridge University Press.

Winter, Yoad. 1997. Choice functions and the scopal semantics of indefinites. Linguistics \& Philosophy 20. 399-467.

Zwicky, Arnold M. 1995. What is a clitic? In Joel A. Nevis, Brian D. Joseph, Dieter Wanner, \& Arnold M. Zwicky (eds.), Clitics: A comprehensive bibliography, 1892-1991, xii-xix. Amsterdam: John Benjamins.

Zwicky, Arnold M. 1985. Clitics and particles. Language 61(2). 283-305. 
